\title{
Absorbed in the task: Personality measures predict engagement during task performance as tracked by error negativity and asymmetrical frontal activity
}

\author{
MatTIE Tops \\ University of Groningen, Groningen, The Netherlands \\ University of Leiden, Leiden, The Netherlands \\ and Leiden University Medical Center, Leiden, The Netherlands \\ AND \\ MaARTen A. S. Boksem \\ Radboud University, Nijmegen, The Netherlands \\ and Erasmus University, Rotterdam, The Netherlands
}

\begin{abstract}
We hypothesized that interactions between traits and context predict task engagement, as measured by the amplitude of the error-related negativity (ERN), performance, and relative frontal activity asymmetry (RFA). In Study 1, we found that drive for reward, absorption, and constraint independently predicted self-reported persistence. We hypothesized that, during a prolonged monotonous task, absorption would predict initial ERN amplitudes, constraint would delay declines in ERN amplitudes and deterioration of performance, and drive for reward would predict left RFA when a reward could be obtained. Study 2, employing EEG recordings, confirmed our predictions. The results showed that most traits that have in previous research been related to ERN amplitudes have a relationship with the motivational trait persistence in common. In addition, trait-context combinations that are likely associated with increased engagement predict larger ERN amplitudes and RFA. Together, these results support the hypothesis that engagement may be a common underlying factor predicting ERN amplitude.
\end{abstract}

Event-related potential (ERP) studies have revealed a neural response to errors that has been termed the errorrelated negativity (ERN) or error negativity $(\mathrm{Ne})$ (Falkenstein, Hohnsbein, Hoormann, \& Blanke, 1990; Gehring, Coles, Meyer, \& Donchin, 1990). The ERN is a negative ERP with a frontocentral scalp distribution, peaking 60$110 \mathrm{msec}$ after an error response, and is thought to be generated by the anterior cingulate cortex (ACC). Like studies of ACC function, recent studies of the ERN have increasingly focused on the motivational, emotional, and/ or reward-related processes that are often part of the optimal performance of cognitive tasks.

Many studies have related ERN amplitude to individual differences that reflect punishment sensitivity, neuroticism, or negative emotionality (e.g., Boksem, Tops, Kostermans, \& De Cremer, 2008; Boksem, Tops, Wester, Meijman, \& Lorist, 2006; Hajcak, McDonald, \& Simons, 2004; Luu, Collins, \& Tucker, 2000; Pailing \& Segalowitz, 2004; Tops, Boksem, Wester, Lorist, \& Meijman, 2006). However, ERN amplitude has also been positively related to positive traits, such as agreeableness, empathy, and socialization (Santesso \& Segal- owitz, 2009; Santesso, Segalowitz, \& Schmidt, 2005; Tops et al., 2006). ${ }^{1}$ To reconcile this seeming contradiction, it has been suggested that the ERN reflects task engagement (Cavanagh \& Allen, 2008; Luu et al., 2000; Tops et al., 2006) or concern with the outcome of events (Boksem et al., 2008; Hajcak, Moser, Yeung, \& Simons, 2005; Santesso \& Segalowitz, 2009). We defined engagement as the overt or covert allocation or focusing of attentional resources. Consistent with engagement's determining ERN amplitude, a recent study showed that ERN amplitude was highest in individuals showing a happy mood state and low self-reported boredom at the beginning of the task and showed the largest decrease in a happy mood and the smallest increase in boredom during the task, suggesting in this case a positive relation to intrinsic motivation that is present only at the beginning of performance (West \& Travers, 2008). Another motivator of task engagement may be concerns over social evaluation, which may explain associations between ERN amplitude and measures of negative emotionality, which correlate with such concerns (Boksem \& Tops, 2008; Hajcak et al., 2005; Tops et al., 2006). 
The ERN appears to reflect both trait differences in engagement and state variations in engagement, and contextual interactions between both. For example, Luu et al. (2000) found that subjects scoring high on negative affectivity, who were dissatisfied with their performance, showed a characteristic pattern of overengaging and then disengaging from the task, as reflected in the amplitude of the ERN during prolonged task performance. Changes in the amplitude of the ERN to performance feedback have been related to changes in self-reported engagement during a task (Yeung, Holroyd, \& Cohen, 2005). In previous studies, using a task that required continuous performance for a rather long period of time $(2.5 \mathrm{~h})$, we found that the amplitude of the ERN decreased during task performance (most dramatically within the first $30 \mathrm{~min}$ ) but increased again after providing the subjects with an opportunity to win a monetary reward by performing well (Boksem, Meijman, \& Lorist, 2006; Tops et al., 2006). We suggested that this may reflect reduced intrinsic engagement while performing a monotonous (i.e., boring), fatiguing task, compensated by extrinsic engagement after the reward manipulation.

In the present study, we had to tackle the problem of how to predict momentary state levels of engagement during task performance as reflected in physiological measures such as the ERN. A starting point could be to use measures of individual differences in motivation as predictors. However, motivation is not a one-dimensional construct, and moreover, different forms of motivation may interact with different context parameters to determine actual momentary task engagement. For instance, engagement specifically after a reward manipulation may be best predicted by a measure of individual differences in the motivation to spend effort to obtain reward, whereas without such a manipulation, engagement may be better predicted by a more general measure of individual differences in habitual intrinsic engagement. As a first test of this hypothesis, we had a large group of subjects fill out measures of individual differences that included a measure of the motivation to obtain rewards (drive for reward) and a measure of habitual high intrinsic engagement (referred to in the personality literature as absorption [e.g., Tellegen, 1985] or attentional resource allocation [Carleton, Abrams, \& Asmundson, 2010]). In addition, the subjects filled out a scale measuring persistence (Cloninger, Pryzbeck, Svrakic, \& Wetzel, 1994) that, on the basis of its contents, should most directly and generally reflect the motivation to persist in frustrating and prolonged task performance, such as in the prolonged time-on-task paradigm we used in Study 2. We tested whether absorption and drive for reward specifically, and perhaps also other measures, would contribute significantly and independently to the prediction of these persistence scores. It turned out in Study 1 that persistence was predicted independently by absorption, drive for reward, and constraint. The prediction by constraint fits the relationship this trait has with impulse control, self-discipline, dutifulness, resisting fatigue and temptations, and effortful control of behavior in the service of long-range goals and with engagement, but not disengagement, responses to adversity (Carver \& Connor-Smith, 2010; De Fruyt, McCrae, Szimák, \& Nagy,
2004; MacDonald, 2008; Segerstrom, 2005), which would increase persistence during prolonged task performance.

In a second study, we used the independent measures from the first study to predict engagement in the context of prolonged task performance, using psychophysiological measures. We predicted a personality $\times$ context interaction such that absorption would predict engagement primarily at the start of performance, whereas drive for reward would predict engagement after the reward manipulation, when rewards could be obtained for good performance. In addition, constraint would prevent or delay declines in engagement.

Importantly, engagement that results from different forms of motivation may (partly) involve different neurophysiological systems, and hence, different psychophysiological measures may be differently sensitive to specific forms of engagement. Drive for reward and related measures have been associated with resting-state relative frontal asymmetrical activity (RFA) that is biased toward the left, as measured by the difference between left and right midfrontal alpha power (Amodio, Master, Yee, \& Taylor, 2008; Balconi \& Mazza, 2010; Coan \& Allen, 2003; De Pascalis, Varriale, \& D'Antuono, 2010; Harmon-Jones \& Allen, 1997), and specifically, drive for reward predicted a similar asymmetry measure in a functional magnetic resonance imaging (fMRI) study (Berkman \& Lieberman, 2010). Left RFA is thought to reflect approach motivation - that is, the motivation for behavior to obtain rewards (Davidson, 1992; Harmon-Jones, Gable, \& Peterson, 2010). Drive for reward was also related to a larger ERN to performance feedback in a go/no-go task in which subjects could win and lose money contingent on the correctness of the (non) response (De Pascalis et al., 2010).

In the present study, we attempted to track momentary engagement during prolonged task performance and after a reward manipulation, using individual differences in personality traits as predictors and EEG/ERP as online measures. We measured individual differences in absorption and drive for reward, using questionnaire measures, and determined their specificity and independency in predicting that self-reported motivation would persist in frustrating and prolonged task performance in Study 1. We found that drive for reward and absorption, together with constraint, predicted persistence scores. In Study 2, we had subjects perform a monotonous cognitive task for a prolonged time. For the last part of the task, we motivated the subjects by promising them a monetary reward for good performance. We used RFA and ERN amplitude and performance as measures of engagement during the task. We predicted that absorption would predict larger ERN amplitudes during the first part of performance, constraint would prevent or delay declines in ERN amplitudes and deterioration of performance, and drive for reward would predict left RFA when a reward could be obtained.

\section{STUDY 1}

\section{Method}

Subjects

Eighty-eight healthy female introductory psychology students, between 18 and 35 years of age $(M=21, S D=3.4)$, filled out the 
Table 1

Correlations From Studies 1 and 2 Between Persistence-Related Traits

\begin{tabular}{lcccccccc}
\hline \multicolumn{1}{c}{ Trait } & Pers. & Drive & Cons. & Abs. & Rew. & BIS & Agree. & Neur. \\
\hline Persistence & & $.59^{* *}$ & .13 & $.44^{*}$ & $.34^{\dagger}$ & .16 & -.08 & .20 \\
Drive for reward & $.50^{* * *}$ & & -.09 & .17 & .27 & .26 & .03 & .30 \\
Constraint & $.39^{* * *}$ & $.23^{*}$ & & -.04 & -.09 & .20 & -.31 & .13 \\
Absorption & $.31^{* *}$ & .06 & .07 & & .23 & .12 & .24 & $.35^{\dagger}$ \\
Reward responsivity & $.29^{* *}$ & $.49^{* * *}$ & .07 & $.18^{\dagger}$ & & .21 & -.09 & .17 \\
BIS & $.29^{* *}$ & $.26^{*}$ & $.47^{* * *}$ & $.33^{* *}$ & $.26^{*}$ & & $.40^{\dagger}$ & $.56^{* *}$ \\
Agreeableness & $.20^{\dagger}$ & .13 & -.07 & $.28^{* *}$ & .09 & $.37^{* * *}$ & .13 \\
Neuroticism & $.21^{*}$ & $-.19^{\dagger}$ & $.25^{*}$ & $.40^{* * *}$ & .16 & $.58^{* * *}$ & .09 & .09 \\
\hline
\end{tabular}

Note-Only traits that showed significant correlations with persistence are shown. Correlations from Study 1 are reported below the diagonal $(n=88)$; correlations from Study 2 are reported above the diagonal $(n=24) . \quad{ }^{\dagger} p<.10 . \quad{ }^{*} p<.05 .{ }^{* *} p<.01 .{ }^{* * *} p<.001$.

questionnaires. Their participation was an obligatory part of their study. Written informed consent was obtained prior to the study.

\section{Questionnaires}

BIS/BAS scales. We used the Behavioral Inhibition System (BIS) subscale from the Dutch version (Franken, Muris, \& Rossin, 2005) of the BIS/BAS scale created by Carver and White (1994) to assess dispositional punishment sensitivity. This BIS scale (range: 7-28) consists of seven items that subjects endorse on a 4-point scale from 1 (very true for me) to 4 (very false for me). Of the three Behavioral Activation System (BAS) scales, the drive for reward scale (four items; range: 4-16) measures motivation to expend effort to obtain reward. An example item is "I go out of my way to get things I want." Fun seeking (four items; range: 4-16) measures impulsive pursuit of pleasure and new experiences, and reward responsiveness (five items; range: 5-20) measures excitement after getting a reward.

Five-Factor Personality Inventory (FFPI). We used the 100item FFPI to assess extraversion, agreeableness, constraint, neuroticism, and autonomy (Hendriks, Hofstee, \& De Raad, 1999). An example item of constraint is "does things according to a plan." Every scale has 20 items, which are answered on a scale from 1 (not at all applicable) to 5 (very much applicable). Orthogonalized FFPI factor scores were computed using the FFPI scoring software available from the FFPI authors (Hendriks et al., 1999). Raw-score Cronbach's alphas range from .85 to .91 (De Fruyt et al., 2004).

Temperament and Character Inventory (TCI). This questionnaire measures four temperament and three character dimensions of Cloninger's psychological model of personality. We used only the four temperament dimensions of the TCI, which consist of a total of 60 items, assessing novelty seeking (and its four subscales: exploratory excitability, impulsivity, extravagance, and disorderliness), harm avoidance (and its subscales: shyness with strangers, fear of uncertainty, worry, and fatigability-asthenia), reward dependency (with three subscales: attachment-detachment, sentimentality, and dependency), and persistence (Cloninger et al., 1994; De la Rie, Duijsens, \& Cloninger, 1998). All the subscales and persistence consist of five items. An example item of persistence is "I'm often so determined that I continue working long after other people give up." Absorption was measured using the sentimentality subscale of the reward dependency scale. An example item is "I probably cry more easily than most people during a sad movie." The items on this scale measure imaginative involvement of the kind that was proposed on the basis of a large factor analysis of absorption and dissociation scales to measure the absorption component of attentional resource allocation (Carleton et al., 2010). This scale was found, in a large twin study, to share a genetic basis with other facets of absorption, such as self-forgetfulness and transpersonal identification, and to share environmental influences with both these and, additionally, persistence and empathy facets, such as compassion (Ando et al., 2004).

General health questionnaire. This questionnaire included questions about the number of cigarettes and cups of coffee subjects consume per day, the number of alcoholic consumptions per week, and the number and types of drugs used in the last 6 months.

\section{Results}

All the questionnaire scores were in normal ranges for healthy populations. Six traits were significantly related to persistence, all showing positive correlations (and agreeableness related positively to persistence at the trend level; see Table 1). Other correlations included relations between constraint and less novelty seeking $(r=-.61, p<$ $.00001)$, less BAS fun seeking $(r=-.52, p<.00001)$, less extraversion $(r=-.21, p<.05)$, more worry $(r=$ $.39, p<.001)$, more fear of uncertainty $(r=.39, p<$ $.001)$, and higher fatigability $(r=.21, p<.05)$. Absorption likewise was related to more worry $(r=.23, p<.05)$ and more fear of uncertainty $(r=.32, p<.01)$. Both constraint and absorption were related to reporting less use of cigarettes $(r=-.29$ and $r=-.28, p \mathrm{~s}<.01)$ and drugs $(r=-.35$ and $r=-.25, p \mathrm{~s}<.02)$, whereas constraint also was related to less alcohol consumption $(r=-.31$, $p<.01)$ and absorption to less coffee consumption $(r=$ $-.27, p<.01)$.

We performed an exploratory principal components analysis to find out whether the eight interrelated traits could be reduced to a lower number of components that are related to motivation. On the basis of the criterion of component eigenvalues $\geq 1$ and a scree plot, this analysis produced three components that explained $65 \%$ of the variance in the trait scores (see Table 2 for the component matrix). We think that in motivational terms, the components may be reasonably described by the highest loading trait: Component I seems to reflect a drive for reward that increases persistence, Component II seems to reflect persistence motivated by constraint and social evaluative concerns that also lead to worry or anxious apprehension that

Table 2

Varimax Rotated Component Matrix of Traits

\begin{tabular}{llll}
\hline \multicolumn{1}{c}{ Trait } & I & II & III \\
\hline Drive for reward & .86 & & \\
Reward responsivity & .78 & & \\
Persistence & .64 & .36 & \\
Constraint & & .84 & \\
BIS & & .72 & .45 \\
Neuroticism & & .64 & .42 \\
Absorption & & & .77 \\
Agreeableness & & & .71 \\
\% Variance explained & 23 & 23 & 20 \\
\hline
\end{tabular}

Note-Only component loadings $>20$ are shown. 
are reflected in BIS and neuroticism scores, and Component III reflects absorption or habitual attentional resource allocation. Interestingly, although all four traits loading on Component III correlated positively with persistence, persistence does not load on this component. In hindsight, this makes sense, since we thought that absorption was related to habitual intrinsic motivation, which may be high during performance of new or changing tasks, but was not strongly related to persistence of engagement during long or boring tasks, as measured by the persistence scores.

Although the constraint factor of Big 5 personality models is usually referred to as conscientiousness, a comparison of the presently used FFPI with the revised NEO-Personality Inventory (NEO-PI-R) showed that in the FFPI, this factor relates most strongly to the NEO-PI-R facets of order, dutifulness, and self-discipline and negatively to openness to fantasy and openness to actions, reflecting inhibitive aspect of conscientiousness that might be identified by Tellegen's constraint (De Fruyt et al., 2004). This is consistent with the high loadings of BIS and neuroticism on the constraint component. In contrast, the FFPI constraint factor captures less of the proactive aspects of conscientiousness, such as achievement striving and deliberation (De Fruyt et al., 2004). However, the vector of $30^{\circ}$ from constraint in the direction of autonomy shows good correspondence to NEO-PI-R conscientiousness, including higher loadings from achievement striving and proactive facets of extraversion (assertiveness and activity) and increased negative loadings from neuroticism facets (De Fruyt et al., 2004). Hence, we computed this rotated conscientiousness factor and repeated the component analysis from Table 2, using conscientiousness instead of the constraint variable. This analysis resulted in three components similar to those in Table 2. However, conscientiousness loaded on the drive for reward component (.36), on the component with neuroticism and BIS (.65), and on the component with absorption and agreeableness $(-.42)$. This is consistent with conscientiousness containing both proactive and reactive or inhibitive aspects, whereas constraint mainly reflects the inhibitive aspects.

Next, we performed a multiple regression analysis to see whether different motivational "factors" can independently predict persistence. An initial regression analysis including all seven traits as predictors explained $40 \%$ of the variance in persistence $[F(7,80)=7.76, p<.001]$. The only significant predictors were drive for reward (partial $r=.40, p<.001$ ), constraint (partial $r=.32$, $p=.003$ ), and absorption (partial $r=.29, p=.008$ ). We next performed a regression analysis with only the three significant predictors (see Table 3 ). Because traits could be significant predictors when included in the analysis without other correlated traits that overlap in their prediction of persistence, we repeated the regression analysis with the three significant predictors and additionally, one by one, each of the remaining traits. This did not result in additional significant predictors of persistence. The final regression model (Table 3) converges with the component analysis in suggesting the existence in this set of variables of three trait factors that independently contribute to predicting engagement and persistence during performance.
Table 3

Regression Analysis Predicting Persistence Scores

\begin{tabular}{lccccc}
\hline \multicolumn{1}{c}{ Trait } & Beta & $t$ & $p$ & $r$ & $P-r$ \\
\hline & & $R^{2}=40, F(3,84)=18.35, p<.001$ & \\
Drive for reward & .42 & 4.79 & .001 & .50 & .46 \\
Constraint & .27 & 3.10 & .003 & .39 & .32 \\
Absorption & .27 & 3.12 & .003 & .31 & .32 \\
\hline
\end{tabular}

Note $-p$ values apply to both $t$ tests and partial correlations; $r=$ Pearson's correlation between independent variable and persistence; $P-r=$ partial correlation between independent variable and persistence after partialling out the variance of persistence that is explained by the other independent variables.

\section{Discussion}

Seven traits correlated positively with persistence. Interestingly, almost all these traits have been associated with larger ERN amplitudes in previous studies. For instance, reward responsivity and other sensitivity-toreward measures have been related to larger ERN amplitudes (Boksem et al., 2008; Santesso \& Segalowitz, 2009), although the Boksem et al. (2008) result was actually a trait $\times$ context interaction, since ERN amplitudes were positively related to reward responsivity when monetary rewards could be won by performing well but negatively related when monetary rewards could be lost only by bad performance. A trait $\times$ context interaction was also found for conscientiousness, which related to smaller increases in ERN amplitude in response to monetary incentives, possibly because it was associated with high engagement even without incentives (Pailing \& Segalowitz, 2004). The trait of low behavioral control, or constraint, has been related to smaller ERN amplitudes (Stahl \& Gibbons, 2007). Similarly, increased ERN amplitudes have been found in high-socialized individuals, and decreased ERN amplitudes in low-socialized individuals, both when errors were punished (Dikman \& Allen, 2000; Potts, George, Martin, \& Barratt, 2006) and without explicit punishment (Santesso \& Segalowitz, 2009; Santesso et al., 2005). Several studies have associated measures of punishment sensitivity or negative affectivity such as BIS and neuroticism with larger ERN amplitudes (e.g., Boksem et al., 2008; Boksem, Tops, et al., 2006; Hajcak et al., 2004; Luu et al., 2000; Pailing \& Segalowitz, 2004; Tops et al., 2006). Agreeableness and its strong correlate empathetic concern (see note 1) have also been related to larger ERN amplitudes (Larson, Fair, Good, \& Baldwin, 2010; Santesso \& Segalowitz, 2009; Tops et al., 2006). Larson et al. also found a positive association between ERN amplitudes and scores of empathetic fantasy, a measure of absorption. Moreover, absorption is associated with agreeableness, empathetic concerns, and emotional intensity (e.g., present component analysis; Ando et al., 2004; Wickramasekera, 2007), which have been positively related to ERN amplitude (Dywan, Mathewson, Choma, Rosenfeld, \& Segalowitz, 2008; Larson et al., 2010; Santesso \& Segalowitz, 2009; Tops et al., 2006).

Many of these traits prove to be interrelated and have in common that they are associated with persistence. This is strong support for the hypothesis that the common un- 
derlying factor that predicts the amplitude of the ERN is engagement. However, there would be stronger support if the traits interacted with context to predict the ERN (and RFA), such that trait-context combinations that are likely to be associated with increased engagement predicted larger ERN amplitudes.

The component analysis of persistence and the traits correlated with it produced three independent components. Component I seems to reflect a drive for reward that increases persistence; Component II seems to reflect persistence motivated by constraint and social evaluative concerns that also lead to worry or anxious apprehension that are reflected in BIS and neuroticism scores; and Component III seems to reflect absorption or habitual attentional resource allocation. A regression analysis showed that drive for reward, constraint, and absorption independently predict persistence.

In Study 2, we tested whether trait-context interactions that are likely to be associated with differential engagement predict differences in physiological indicators of engagement (ERN and RFA). We had subjects perform a monotonous cognitive task for a prolonged time. For the last part of the task, we motivated the subjects by promising them a monetary reward for good performance. We predicted that absorption would predict larger ERN amplitudes during the first part of performance, whereas drive for reward would predict left RFA when a reward could be obtained. Constraint would relate to a smaller or delayed decline in ERN and performance during prolonged performance.

\section{STUDY 2}

\section{Method}

\section{Subjects}

Twenty-four healthy right-handed female participants, between 18 and 27 years of age $(M=20, S D=3.6)$, were recruited from the university population. They were paid for their participation and had normal or corrected-to-normal vision. None of the subjects worked night shifts or used prescription medication. Written informed consent was obtained prior to the study.

\section{Task}

We used a version of the Eriksen flanker task (Eriksen \& Eriksen, 1974). On each trial, a five-letter string was presented. The central letter was the target, the remaining letters the flankers. The stimuli used for targets and flankers were the letters $\mathrm{H}$ and S. During the entire task, a fixation mark was displayed $0.14^{\circ}$ above the target letter. On congruent trials, the target letter was the same as the flankers (SSSSS or $\mathrm{HHHHH}$ ); on incongruent trials, the target letter differed from the flankers (SSHSS or HHSHH). Of the trials, $40 \%$ consisted of incongruent stimuli, and $60 \%$ consisted of congruent stimuli. Congruent and incongruent trials were presented in random order.

The stimuli were presented on a 17 -in. monitor. The letters were white against a black background, and each letter had a height and width of $0.24^{\circ}$ of visual angle. Eriksen and Eriksen (1974) showed that reaction times (RTs) and error rates were highest when the letters were presented close together. Therefore, we presented the letters $0.05^{\circ}$ apart. The complete five-letter string had a width of $1.43^{\circ}$ of visual angle.

In addition, flankers were presented $100 \mathrm{msec}$ prior to target onset in order to maximize the expected flanker compatibility effect
(Kopp, Rist, \& Mattler, 1996). The target and flankers disappeared simultaneously the moment a response was made. In cases in which no response was given, the targets and flankers disappeared after $1,200 \mathrm{msec}$. The interstimulus interval was $3 \mathrm{sec}$. The subjects received six intervals of 400 trials. Each interval had a total duration of $20 \mathrm{~min}$.

After six intervals, the subjects received additional information by means of a text message on the screen: the reward condition. The subjects were informed that they were about to begin the last part of the experiment and that they could earn points by responding correctly. For each correct response, the subjects would receive 10 points. For every incorrect response, the subjects would lose 20 points. Responding too slowly or not at all resulted in no points. Finally, the subjects were told that their performance would be compared with that of the other subjects; the 10 subjects with the highest score would receive an extra monetary reward of $€ 20$. After this information had been given, a last interval consisting of 388 trials was presented. After every 97 trials, the subjects received feedback about the number of points they had scored. The duration of the complete task was $2 \mathrm{~h} 20 \mathrm{~min}$.

\section{Questionnaires}

The same personality questionnaires were used as in Study 1. In addition, a posttask questionnaire asked the subjects whether they had experienced increased fatigue with time on task and whether they had had problems concentrating (yes/no). We will now focus on drive for reward, absorption, and constraint.

Drive for reward. This BAS drive-for-reward scale (range: 4-16) consists of four items that subjects endorse on a 4-point scale from 1 (very true for me) to 4 (very false for me). Cronbach's alpha of the drive-for-reward scale was .79 .

Absorption. Absorption was measured using the same TCI scale as in Study 1. This subscale comprises five statements that are either endorsed or not by the subject and had a Cronbach's alpha of .81 in this study. Scores ranged from 0 to 5 .

Constraint. Constraint was measured using the same 20-item scale as in Study 1, the items of which are answered on a scale from 1 (not at all applicable) to 5 (very much applicable). Orthogonalized factor score was computed using the FFPI scoring software available from the FFPI authors (Hendriks et al., 1999).

Profile of Mood States (POMS). The 32-item POMS was used to assess mood before and after the subjects completed the experimental task. The five subscales measure sadness (range: 0-32), fatigue (0-24), vigor $(0-20)$, anger $(0-28)$, and tension (0-24) (Wald \& Mellenberg, 1990).

\section{Procedure}

The subjects were instructed to abstain from alcohol $24 \mathrm{~h}$ before the experiment and from caffeine-containing substances $12 \mathrm{~h}$ before the experiment. After arrival at the laboratory at 12.00 hours, the subjects were given written task instructions, whereafter they were trained in performing the task for $15 \mathrm{~min}$. Following the application of the electrodes, the subjects were seated in a dimly lit, soundattenuated, electrically shielded room at $1.20 \mathrm{~m}$ from the screen. The subjects had to surrender their watches, so they had no idea of time. Their index fingers rested on touch-sensitive response boxes. The subjects were instructed to lift their fingers from the response button as quickly as possible when a target was presented, maintaining a high level of accuracy. Immediately before and after task performance, mood states were rated. No breaks were given.

\section{Electrophysiological Recording and Data Reduction}

The EEG was recorded using $60 \mathrm{Sn}$ electrodes attached to an electro-cap (Electro-Cap International). All electrodes were referenced to linked earlobes. The electro-oculogram (EOG) was recorded bipolarily from the outer canthi of both eyes and above and below the left eye, using $\mathrm{Sn}$ electrodes. Electrode impedance was kept below $5 \mathrm{k} \Omega$. EEG and EOG were amplified with a 10 -sec time 
constant and a 200-Hz low-pass filter, sampled at $1000 \mathrm{~Hz}$, digitally low-pass filtered with a cutoff frequency of $70 \mathrm{~Hz}$, and online reduced to a sample frequency of $250 \mathrm{~Hz}$.

All ERP analyses were performed using the Brain Vision Analyzer software (Brain Products). ERPs were averaged offline. The data were further filtered with a $0.53-\mathrm{Hz}$ high-pass filter with a slope of $48 \mathrm{~dB} /$ oct and a $40-\mathrm{Hz}$ low-pass filter with a slope of $48 \mathrm{~dB} /$ oct. Out-of-range artifacts were rejected, and eye movement artifacts were corrected, using the Gratton, Coles, and Donchin (1983) method. A baseline voltage over the $200-\mathrm{msec}$ interval preceding the response was subtracted from the averages.

\section{Data Analysis}

Performance. For the different stimulus conditions, mean RTs were calculated. Cronbach's alpha for RTs over the seven intervals was .97 . Correct reactions occurring within a 150 - to $1,000-\mathrm{msec}$ interval after stimulus presentation were considered as hits (Cronbach's alpha was .91). On incongruent trials of the flanker task, typically more errors are made, and RTs are longer than on congruent trials. We calculated the congruity effect on errors (Cronbach's alpha was .89) and on RTs (Cronbach's alpha was .89) by subtracting the mean performance on congruent trials from the mean performance on incongruent trials. For RT measures, we used only data from correct trials following correct trials. To investigate strategic changes after error detection, we analyzed RTs on correct trials following an error minus RTs on correct trials following a correct response (i.e., posterror slowing; Rabbit, 1966). Since we found no difference in posterror slowing for congruent and incongruent $n-1$ trials, our measure of posterror slowing included both. Cronbach's alpha was .79 .

ERPs. Mean ERN amplitudes were calculated at $\mathrm{FCz}$, where visual inspection showed that this component was maximal. We quantified the ERN as the most negative peak occurring in the $100 \mathrm{msec}$ following the response. For statistical analyses, we used the average amplitude of the ERN in a time window starting $12 \mathrm{msec}$ before the peak until $12 \mathrm{msec}$ after the peak. The mean number of errors $(S D)$ per subject over which the ERN was calculated was, for each interval, 21.1 (13.5), 25.1 (13.6), 24.9 (12.6), 28.1 (17.6), 28.7 (16.9), 27.4 (11.2), and 20.9 (12.3). Cronbach's alpha of ERN over the seven intervals was .93. We also analyzed stimulus-locked ERPs and the positivity preceding the ERN to rule out relationships with the predictors. Since no relationships were found, they are not described.

Alpha asymmetry. The time period during which the subjects were working on the task in every interval was segmented into 50\%-overlapping 5.12-sec segments. After artifact detection and ocular correction as described above, the data were submitted to a fast Fourier transform (FFT), using a 100\% Hanning window. Using this window results in complete attenuation of the jump discontinuity effect caused by performing FFT on segmented EEG data, whereas using a $50 \%$ overlap ensures that data at the edge of one segment (where it is dampened the full $100 \%$ ) is not attenuated at all in the next segment, thus minimizing data loss due to this attenuation of data near the edges of the segments. Segments were averaged and then log-transformed to normalize the distributions.

Because alpha power (activity in the 8 - to $12-\mathrm{Hz}$ frequency range) is inversely related to cortical activity (Laufs et al., 2003), averaged spectral power within the alpha frequency range was calculated for every electrode. To obtain a measure of left-right asymmetry in frontal brain activation, asymmetry scores were calculated for homologous frontal electrodes (F3 and F4) by subtracting the spectral power value for the left side from that for the right side $(\mathrm{F} 4-\mathrm{F} 3)$. This was also done to control for individual differences from nonneural sources such as skull thickness (Pivik et al., 1993; Tomarken, Davidson, Wheeler, \& Doss, 1992). For alpha power, positive RFA scores reflect greater left-sided neural activity. We present asymmetry results only from electrodes F3/F4, which are most consistently reported over studies of approach/avoidance motivation. The asymmetry results we present were maximal at F3/F4 and were not pres- ent at parietal, temporal, or occipital electrodes. Cronbach's alpha of RFA over the seven intervals was .88.

\section{Statistical Analyses}

The variables used as predictors in this study did not predict stimulus-locked ERPs; hence, we will present only the responselocked ERN that has been suggested to reflect task engagement. As in our previous studies and the studies of others, the measures of individual differences predicted ERN amplitudes on error trials, but not on correct trials. Hence, as in our previous studies, we present the results regarding ERN on error trials.

For each outcome measure, we performed a GLM analysis with seven levels of time as a within-subjects factor to test whether the measure would show the expected linear change, with time on task or quadratic change reflecting the reward manipulation for the last (seventh) interval. We then performed GLM analyses of each outcome measure, with seven levels of time as a within-subjects factor, flanker congruity as a within-subjects factor where applicable, and drive for reward, constraint, and absorption as continuous betweensubjects factors (i.e., as predictors). Following up on significant interactions, we calculated partial correlations between the predictor and the outcome measure to describe the direction of effects. To follow up interactions involving time, we calculated partial correlations between predictors and change in outcome measures; change over a time period was calculated as the value of the last interval minus the value of the first interval.

\section{Results}

The mean constraint score was $0.69(S D=1.05)$, the mean absorption score was $3.46(S D=1.28)$, and the mean drive for reward score was $12.92(S D=1.82)$ (see Table 1 for the correlations between the predictors).

\section{ERN}

The ERN showed both a linear decrease $[F(1,23)=$ 22.06, $p<.0001]$ and a quadratic change reflecting a large decrease from Interval $1(M=-9.08 \mu \mathrm{V}, S D=7.51)$ to Interval $2(M=-5.27, S D=5.87)$ and continued more gradually toward Interval $6(M=-1.42, S D=3.52)$, followed by an increase after the reward manipulation $(M=$ $-4.48, S D=4.80)[F(1,23)=32.96, p<.0001]$. A GLM analysis of ERN amplitude, with seven levels of time as a within-subjects factor and drive for reward, constraint, and absorption as continuous between-subjects factors (i.e., as predictors), showed a main effect of absorption $[F(1,20)=4.12, p<.05]$, a linear absorption $\times$ time interaction $[F(1,20)=6.85, p<.02]$, a linear drive for reward $\times$ time interaction $[F(1,20)=5.06, p<.05]$, and a trend-level linear constraint $\times$ time interaction $[F(1,20)=$ $3.38, p<.10$ ], but no other main effects or interactions. Following up on the interactions between predictors and time, we calculated partial correlations between each predictor and ERN amplitude at each time interval and between each predictor and the decrease in ERN amplitude from the first to the last prereward manipulation interval. As is shown in Table 4, absorption was related to a more negative ERN in the first interval (see also Figures 1A and 2), but also to a larger decrease in ERN amplitude from the first to the last prereward manipulation interval. Drive for reward showed the same pattern, although it was not independently related significantly to the ERN at any interval. Constraint was related to a smaller decrease of 
Table 4

Partial Correlations Between Predictors and Dependent Variables

\begin{tabular}{lcccccc}
\hline \multicolumn{1}{c}{ Traits } & ERN1 & $\Delta$ ERN & RFA1 & mRFA & RFA7 & $\Delta$ RFA \\
\hline Drive for reward & -.35 & .31 & .30 & .20 & $.49^{*}$ & $.42^{*}$ \\
Constraint & .16 & $-.44^{*}$ & $.51^{*}$ & $.42^{*}$ & $.36^{\dagger}$ & .01 \\
Absorption & $-.60^{* *}$ & $.70^{* * *}$ & $-.58^{* *}$ & $-.52^{*}$ & -.30 & .06 \\
\hline
\end{tabular}

Note $-\triangle E R N=E R N$ amplitude in Interval 1 (ERN1) minus amplitude in Interval 6 (a positive value is an increase); numbers 1 and 7 denote interval numbers; mRFA = mean relative frontal asymmetry over the six prereward manipulation intervals (a positive value means relatively more activity on the left); $\triangle \mathrm{RFA}=$ RFA7 minus RFA6 (a positive value means a shift to the left after the reward manipulation). ${ }^{\dagger} p<.10 .{ }^{*} p<.05 .{ }^{* *} p<.01 .{ }^{* * *} p<.001$.

the ERN during the task. No predictor was related to the increase in ERN after the reward manipulation. The Pearson's correlations between the predictors and the same ERN measures are shown in Table 5.

\section{RFA}

RFA showed a linear shift to the right from Interval $1(M=.081 \mu \mathrm{V} / \mathrm{Hz}, S D=.094)$ to Interval $6(M=$ $.059, S D=.083)$ and Interval $7(M=.068, S D=.093)$ $[F(1,23)=6.01, p<.05]$. There was a main effect of constraint $[F(1,20)=9.06, p<.01]$, a main effect of absorption $[F(1,20)=6.51, p<.02]$, and a quadratic drive for reward $\times$ time interaction $[F(1,20)=5.63, p<.05]$.
Although, without the predictors, there was no significant change in RFA after the reward manipulation, with the predictors there was a significant shift to the left after the reward manipulation $[F(1,20)=7.34, p<.02]$ and a prediction by drive for reward of a leftward shift after the reward manipulation $[F(1,20)=8.05, p<.02$; see Figure 1D]. As illustrated by the follow-up partial correlations in Table 4, constraint related to left RFA (Figure 1C), whereas absorption related to right RFA (Figure 1B) throughout performance. To check whether the effects were specific for frontal electrodes, we repeated the analyses for all the electrodes. Asymmetry was similarly and significantly predicted only for frontal electrodes
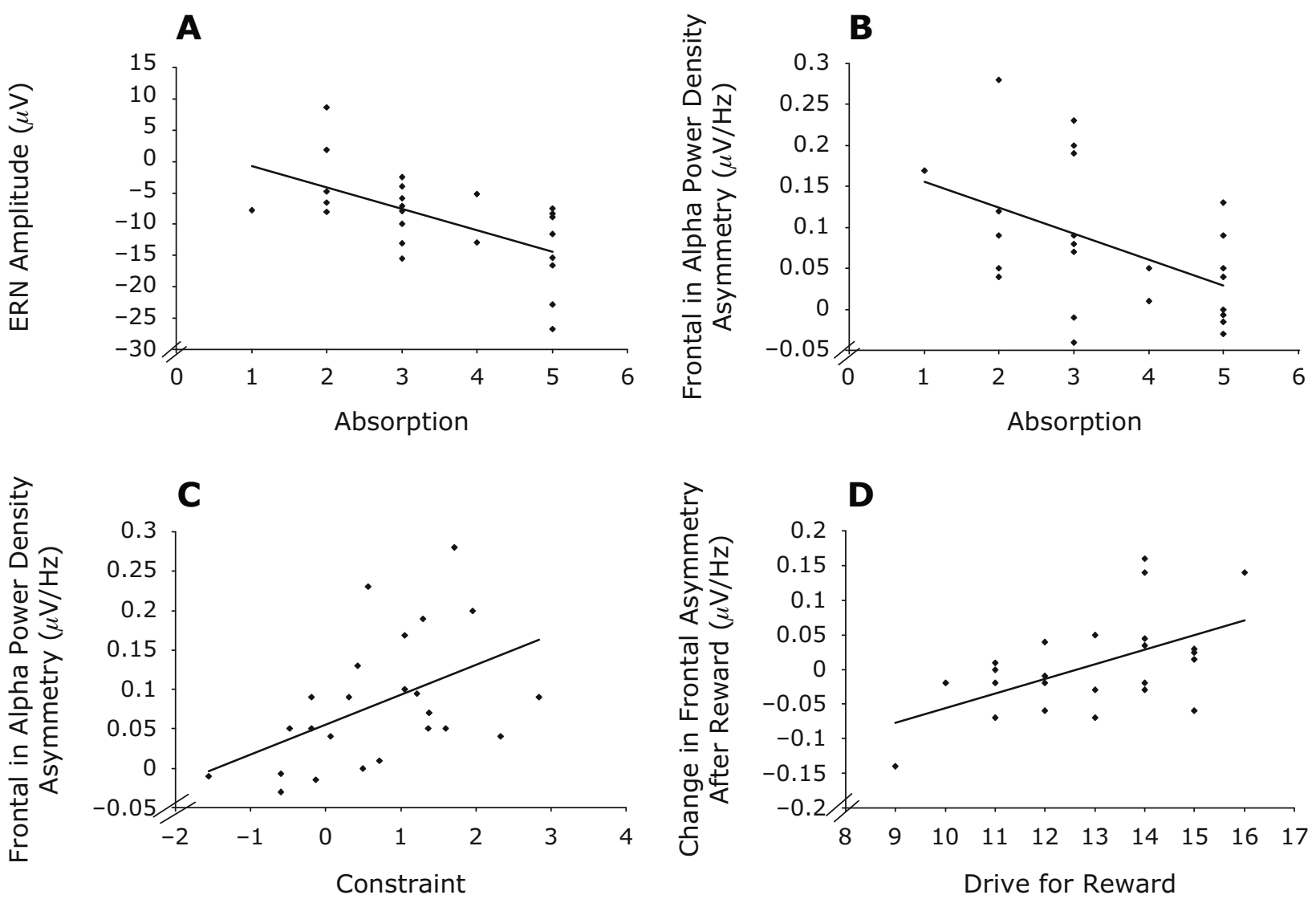

Figure 1. Scatterplots of (A) error-related negativity (ERN) amplitude in the first interval as a function of absorption. (B) Frontal asymmetry in the first interval as a function of absorption. (C) Frontal asymmetry in the first interval as a function of constraint. (D) Change in frontal asymmetry after the reward manipulation as a function of drive for reward. 

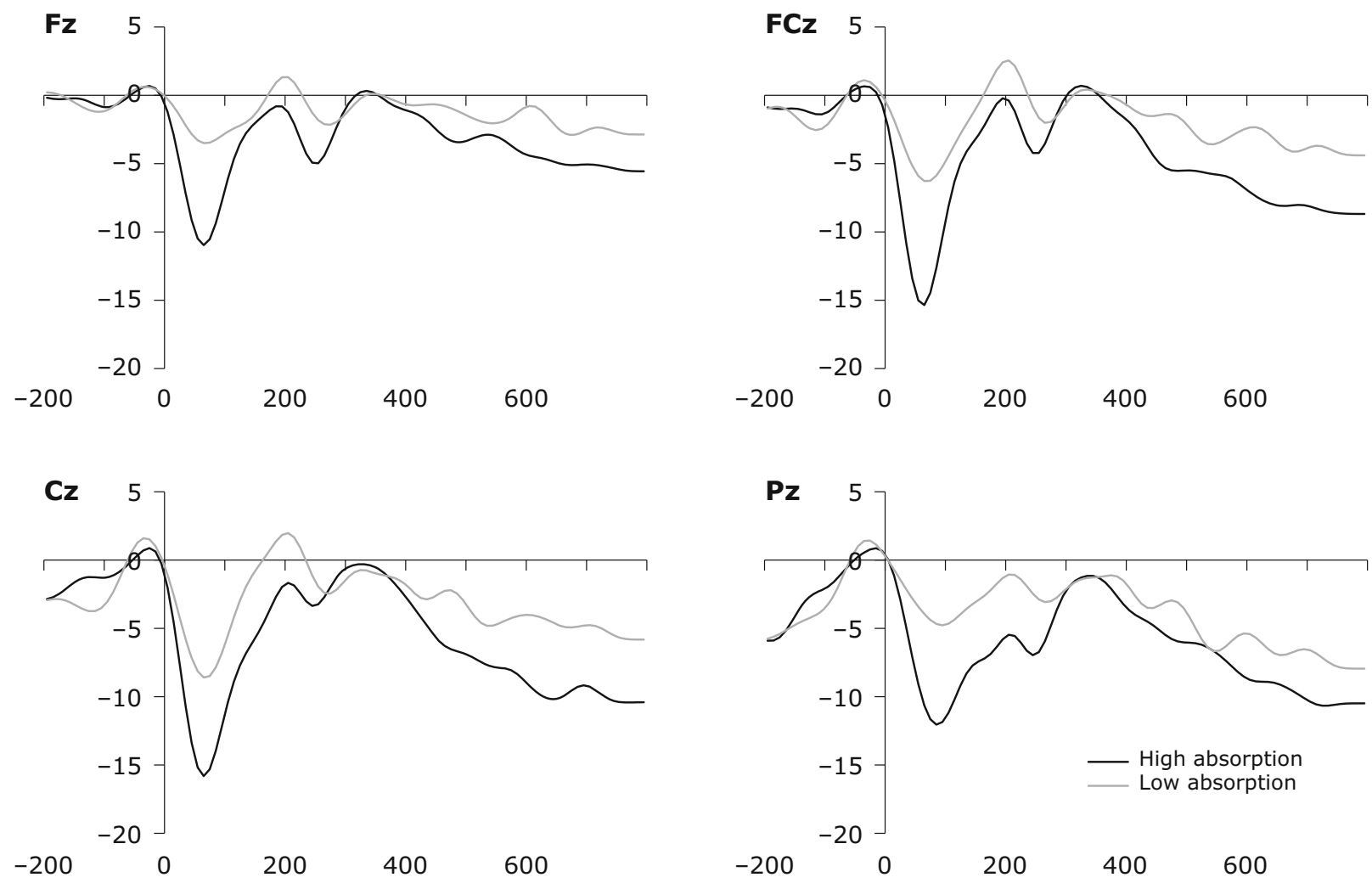

Figure 2. Response-locked event-related potentials from the first interval of 20 min from electrodes $\mathrm{Fz}, \mathrm{FCz}, \mathrm{Cz}$, and $\mathrm{Pz}$ as a function of high (black line) versus low (gray line) absorption scores. Only for graphical purposes, high- and low-scoring groups were created on the basis of median split.

F3/F4, F5/F6, and FC5/FC6, and constraint was additionally related to left RFA at FP1/FP2 and F7/F8.

\section{Errors}

Proportion of errors showed a quadratic change reflecting an increase from Interval $1(M=.06, S D=.04)$ to Interval $6(M=.09, S D=.04)$ and a decrease after the reward manipulation $(M=.07, S D=.04)[F(1,23)=7.75$, $p<.02]$. The proportion of errors was larger on trials with incongruent stimuli $(M=.12, S D=.05)$ than on those with congruent stimuli $(M=.04, S D=.02)[F(1,23)=$ $54.78, p<.0001]$. The GLM analysis with the predictors showed only a trend-level quadratic constraint $\times$ time interaction $[F(1,20)=3.02, p<.10]$. Follow-up partial correlations showed that the quadratic interaction was ex- plained by constraint's tending to be related to fewer errors in the middle intervals (Intervals 3-6: partial $r \mathrm{~s}=-.33$ to -.37 ), but not in the first interval ( $\operatorname{partial} r=-.10$ ) or after the reward manipulation ( $\operatorname{partial} r=.07$ ).

\section{RTs}

The RTs showed both a linear increase $[F(1,23)=8.09$, $p<.009]$ and a quadratic change reflecting an increase from Interval $1(M=464 \mathrm{msec}, S D=61)$ to Interval 6 $(M=514, S D=75)$ and a decrease after the reward manipulation $(M=469, S D=56)[F(1,23)=14.45, p<$ $.001]$. The RTs were longer on trials with incongruent stimuli $(M=514 \mathrm{msec}, S D=64)$ than on those with congruent stimuli $(M=462, S D=69)[F(1,23)=201.37$, $p<.0001]$. There was a linear constraint $\times$ time interac-

Table 5

Correlations Between Predictors and Dependent Variables

\begin{tabular}{lcccccr}
\hline \multicolumn{1}{c}{ Trait } & ERN1 & $\Delta$ ERN & RFA1 & mRFA & RFA7 & $\Delta$ RFA \\
\hline Drive for reward & $-.42^{*}$ & .32 & .13 & .05 & $.41^{*}$ & $.53^{* *}$ \\
Constraint & .13 & $.34^{\dagger}$ & $.44^{*}$ & $.36^{\dagger}$ & .29 & -.04 \\
Absorption & $-.63^{* * *}$ & $-.67^{* * *}$ & $-.46^{*}$ & $-.40^{\dagger}$ & -.19 & .13 \\
\hline
\end{tabular}

Note- $\triangle E R N=$ ERN amplitude in Interval 1 (ERN1) minus amplitude in Interval 6 (a positive value is an increase); numbers 1 and 7 denote interval numbers; $\mathrm{mRFA}=$ mean relative frontal asymmetry over the six prereward manipulation intervals (a positive value means relative more activity on the left); $\triangle \mathrm{RFA}=\mathrm{RFA} 7$ minus RFA6 (a positive value means a shift to the left after the reward manipulation). ${ }^{\dagger} p<.10 .{ }^{*} p<.05 .{ }^{* *} p<.01 .{ }^{* * *} p<.001$. 
tion $[F(1,20)=4.52, p<.05]$, a linear drive for reward $\times$ time interaction $[F(1,20)=5.44, p<.05]$, and a trendlevel drive-for-reward main effect $[F(1,20)=3.09, p<$ .10]. Follow-up partial correlations showed that constraint was related to a larger increase in RTs over intervals (partial $r=.43$ ). Drive for reward was related to shorter RTs in all prereward intervals (partial $r \mathrm{~s}=-.35$ to -.45 ), but not after the reward manipulation (partial $r=-.04$ ), and to a smaller decrease in RT after the reward manipulation (partial $r=-.45$ ).

\section{Posterror Slowing}

Although posterror slowing showed no main effects of time, RTs on trials following errors $(M=465 \mathrm{msec}$, $S D=75$ ) were longer than RTs on trials following correct responses $(M=448, S D=60)$ in the first interval only $[F(1,23)=5.43, p<.05]$. In other intervals, posterror slowing was not significant and varied between $14 \mathrm{msec}$ $(S D=25)$ in Interval 4 and $3 \mathrm{msec}(S D=28)$ in Interval 7. The GLM analysis with the predictors showed only a linear constraint $\times$ time interaction $[F(1,20)=4.10$, $p<.05]$. Follow-up partial correlations showed that constraint was related to an increase in slowing over intervals (partial $r=.41$ ). Note that this effect appears to mirror the effect of constraint on RTs. The correlations between RTs and posterror slowing increased from $r=.18$ in the first interval to $r=.56$ in the fourth interval, then dropping again to $r=.06$ in the last interval.

\section{Mood States}

Sadness $(M=2.4, S D=4.8)$ and tension $(M=2.3$, $S D=3.3$ ) scores did not change during task performance $(p \mathrm{~s}>.10)$. Fatigue increased from $3.5(S D=3.6)$ to 10.2 $(S D=5.6)[t(23)=-5.81, p<.001]$. Vigor decreased from $10.0(S D=3.7)$ to $3.7(S D=3.1)[t(23)=10.38$, $p<.001]$. Anger increased from $1.2(S D=2.5)$ to 4.8 $(S D=4.6)[t(23)=-4.81, p<.001]$. Mean sadness was correlated with absorption $(r=.42, p<.05)$ and with a more negative ERN throughout the task (mean ERN: $r=$ $-.51, p<.02$ ), although this correlation was not present in Interval $7(r=-.08)$. Sadness after the task was correlated with mean right RFA $(r=-.45, p<.05)$, and constraint was associated with less increase of sadness during the task $(r=-.41, p<.05)$. In addition, constraint was associated with higher vigor before $(r=.42, p<.05)$ and after $(r=.69, p<.001)$ the task and with fewer problems concentrating during the task $(r=-.45, p<.05)$. Drive for reward was related to a smaller decrease in vigor during the task $(r=.47, p<.05)$. Drive for reward was also correlated with anger before the task $(r=.48, p<.05)$, but not after the task $(r=.16)$.

\section{GENERAL DISCUSSION}

In Study 2, ERN amplitude, left RFA, and vigor decreased, whereas fatigue, anger, RTs, and error rates increased with time on task. After the reward manipulation, ERN amplitude and left RFA increased, and RTs and error rates decreased. All the measures showed the largest changes from the first to the second 20-min interval of performance and, at the end of the task, from prereward to postreward manipulation. The results of ERN amplitude and performance measures replicate our previous findings (Boksem, Meijman, \& Lorist, 2006; Tops et al., 2006). In addition, we found support that three motivational traits (constraint, absorption, and drive for reward) independently predicted engagement during the task, each trait relating to different contexts (e.g., different variations over time) and outcome measures.

Absorption was related to larger ERN amplitudes at the start of performance, but also to a larger decrease thereafter, consistent with a relation with intrinsic engagement, which is high only at the start of performance. Absorption additionally was related to right RFA and sadness.

In contrast, as time on task increased, but before the reward manipulation, constraint was related to a less pronounced decrease of the ERN, a smaller increase in errors and RTs, and more posterror slowing. Although some of the effects did not reach significance, together they strongly suggest that, with time on task, constraint was related to relatively higher engagement, reflecting conservative strategies to prevent increased error rates (Burton et al., 2009). Constraint also was related to left RFA, a less pronounced increase in sadness during the task, and higher vigor before and especially after the task.

Finally, drive for reward tended to be related to larger ERN amplitudes at the start of performance, shorter RTs (except for the interval following the reward manipulation), and a leftward shift in RFA after the reward manipulation. Drive for reward also was related to a smaller decrease in vigor during the task and to more anger before the task. This pattern seems consistent with a trait reflecting positive motivation to do well and work for reward. We assume that the observed lack of a decrease in RTs after the reward manipulation resulted from the shorter RTs before the manipulation: It may have been less possible for the subjects who scored high on drive for reward to decrease their RTs further.

In Study 1, we showed that most of the traits that have been related to ERN amplitude in previous research are interrelated and have in common that they are correlated with the motivational trait of persistence. This by itself supports the hypothesis that engagement is a common underlying factor that predicts the amplitude of the ERN. An alternative factor, such as concern over social evaluation, may relate to persistence and may perhaps explain the association of traits such as BIS and neuroticism with persistence, but does not seem involved in obvious ways in some of the other traits, such as drive for reward, reward responsivity, and absorption. Moreover, Study 2 provided additional support for the engagement hypothesis by showing that the traits interact with context to predict the ERN, such that trait-context combinations that are likely to be associated with increased engagement predict larger ERN amplitudes.

A recent review of the ERN in terms of psychiatric internalizing disorders, such as obsessive-compulsive disorder, depression, and anxiety disorders, and externalizing disorders, such as attention-deficit hyperactivity disorder, substance abuse, and psychopathy, concluded 
that increased and decreased ERN amplitudes are associated with the internalizing and externalizing dimensions of psychopathology, respectively (Olvet \& Hajcak, 2008). The present results may explain these associations, since constraint, absorption, and persistence have been reported to be increased in internalizing disorders (e.g., Elovainio et al., 2004; Halvorsen et al., 2009; Marchesi, Ampollini, DePanfilis, \& Maggini, 2008) and decreased in externalizing disorders (e.g., Carlson, Booth, Shin, \& Canu, 2002; Cukrowicz, Taylor, Schatschneider, \& Iacono, 2006; Roberts, Jackson, Burger, \& Trautwein, 2009). For instance, obsessive-compulsive personality disorder has been defined as extreme constraint or conscientiousness, and both the disorder and constraint are associated with high perfectionism and fear of uncertainty (Samuel \& Widiger, 2010). In contrast, externalizing psychopathology has been argued to strongly overlap with low constraint (Roberts et al., 2009). Indeed, in the present Study 1, constraint and absorption were related to more trait worry, fear of uncertainty, neuroticism, and fatigability and to less self-reported use of alcohol, drugs, and cigarettes. In a study that showed that the association between depression and the amplitude of the ERN to feedback switched from positive to negative with increasing depression severity, this finding was interpreted as reflecting decreased task engagement with increasing anhedonia (Tucker, Luu, Frishkoff, Quiring, \& Poulsen, 2003). Although this suggests that task engagement may provide a parsimonious account for individual differences in ERN amplitudes at the trait and state levels, it cannot be ruled out that mechanisms behind the ERN are functionally implicated in negative affect or behavioral inhibition (e.g., Tops \& Boksem, in press). More studies are needed to address this unresolved issue.

Since this is the first study to relate changes in ERN amplitude during task performance to a comprehensive and independent set of motivation-related traits, it is difficult to compare the present results with those of previous studies. However, some relationships are at least suggested. The relationship between absorption and ERN amplitudes at the start of the task and the fast reduction in amplitude thereafter appear similar to the relationship between negative affectivity and ERN amplitude reported by Luu et al. (2000), together with increased boredom and a decrease over intervals of initially high posterror slowing. These authors interpreted their findings as initial high engagement and subsequent disengagement in subjects scoring high on negative affectivity. In Study 1, we found that measures that are related to negative affectivity (neuroticism and BIS) loaded on the absorption component. This may suggest that also in the study by Luu and colleagues, it may have been absorption predicting the pattern of results. In another study, the same pattern of engagement and disengagement was predicted by high state happiness and low state boredom at the start of the task and a large decrease in happiness thereafter (West \& Travers, 2008). State positive affect and interest in the task are likely to relate to higher absorption and engagement in the task, and absorption relates moderately to lower trait boredom (the external stimulation aspect of boredom; Culp, 2006).
In addition, a less pronounced increase in state boredom during the task was associated with larger ERN amplitudes (West \& Travers, 2008; see also Luu et al., 2000). Constraint shows strong negative correlations with trait susceptibility to boredom (especially the internal stimulation aspect; Culp, 2006), suggesting that this last association (between less pronounced increase in state boredom during the task and larger ERN amplitudes) may have reflected subjects who score high on constraint, who showed less of an increase in state boredom and a smaller decline during the task in ERN amplitudes.

Consistent with its motivational aspects, drive for reward was related to a larger negative ERN amplitude at the start of performance, although not significantly independently from absorption and constraint. However, drive for reward related specifically to the shift toward left RFA after the reward manipulation. This is consistent with previous associations between drive for reward and left RFA (e.g., Berkman \& Lieberman, 2010; De Pascalis et al., 2010) and with previous findings for drive for reward predicting an increase in other psychophysiological measures - specifically, in a condition in which a monetary reward could be obtained (Boksem et al., 2008; Knyazev \& Slobodskoj-Plisnin, 2007). This suggests that relationships that are usually found with resting RFA can also be found with RFA during a flanker task. This is also suggested by the relationships we found between RFA and mood states. These relations seem consistent with the literature, although, also consistent with the literature, in most cases, mood states did not relate directly to RFA (Harmon-Jones et al., 2010). There was a rightward shift in RFA during task performance, paralleling a decrease in vigor with which it was not correlated. This appears similar to changes during prolonged physical exercise (Woo, Kim, Kim, Petruzzello, \& Hatfield, 2009) and 24 h of sleep deprivation (Ferreira et al., 2006), where rightward RFA shifts paralleled decreases in vigor. Constraint was related to left RFA and less increase in sadness during the task and higher vigor. Drive for reward was related to a smaller decrease in vigor during the task and left RFA after the reward manipulation. Absorption was related to sadness, and both absorption and sadness after the task were related to right RFA. However, the variability in sadness scores was low, suggesting that the results regarding sadness need replication.

Interestingly, a flanker task such as that used in the present experiment activates an inferior frontal gyrus (IFG)/ anterior insula and underlying striatum area (e.g., Wager et al., 2005), and a meta-analysis of emotional-face processing found a relation between approach versus avoidance dimensions and left versus right IFG (Fusar-Poli et al., 2009). Moreover, a recent study using source modeling found support for RFA originating from asymmetrical activity in the IFG (Shackman, McMenamin, Maxwell, Greischar, \& Davidson, 2009). The IFG/anterior insula also consistently show error-related activity (Wittfoth, Küstermann, Fahle, \& Hermann, 2008). This suggests the possibility that RFA during a flanker task may provide a new paradigm for studying asymmetrical brain systems 
involved in traits, motivation, and engagement during performance (see also Tops \& Boksem, in press). The opposite relationships of RFA with constraint and absorption support this suggestion.

Indeed, a striking feature of the present findings is the apparent complementarity of the absorption and constraint motivational factors, with absorption predicting right RFA and initial engagement and constraint predicting left RFA and engagement later on when intrinsic engagement has diminished. Interestingly, absorption and constraint are two factors from the four-factor temperament model of Tellegen (together with positive emotionality and negative emotionality; Tellegen, 1985). Indeed, there is evidence that constraint and absorption are related to opposite hemispherical asymmetry. Tucker, Luu, and Pribram (1995) discussed evidence that constraint is tied to left-hemispherical function. The IFG, in particular, has been implicated in constraint (Whittle, Allen, Lubman, \& Yücel, 2006). The persistence scale from Study 1 was found, in an fMRI study, to be related to increased relatively left-lateralized activity in an IFG-ventral-striatum network (Gusnard et al., 2003). This left-hemisphere system sustains anxious worry and apprehension (Tucker et al., 1995), consistent with the correlation between constraint and worry in the present Study 1. Indeed, anxious apprehension has been related to left-IFG activity (Engels et al., 2007) and left RFA (Mathersul, Williams, Hopkinson, \& Kemp, 2008; Stewart, Levin-Silton, Sass, Heller, \& Miller, 2008), in contrast to anxious arousal, which was associated with right RFA (Stewart et al., 2008). In contrast, the immersion in and absorption by the momentary sensory environment appears associated with the function of a right-lateralized attentional network also involving the IFG and anterior insula (for reviews, see Corbetta \& Shulman, 2002; Craig, 2009; Tops, Boksem, Luu, \& Tucker, 2010). Moreover, absorption is also related to increased intensity of empathy for affect in others (Ando et al., 2004; Wickramasekera, 2007). This may be why agreeableness (another correlate of empathetic concern; see note 1) loaded on the component with absorption in Study 1. In frontotemporal dementia patients, right-ventromedial prefrontal cortex gray matter volume was positively related to agreeableness, whereas volume on the left was negatively related (Rankin et al., 2004), and empathy-related traits were related to a right-ventral hemispheric bias in general (Sollberger et al., 2009). This suggests that the right-lateralized saliency attentional system may be involved in the intensity of empathetic feelings. In light of the literature on absorption and constraint, the opposite relationships with RFA in the present study suggest the possibility that RFA during a flanker task may provide a new paradigm for studying asymmetrical brain systems involved in traits, motivation, and engagement during performance.

Although our paradigm seems suitable for manipulating the level of engagement over time, it is rather restricted in the number and kind of emotions it provokes. Future studies may use tasks that evoke other emotions in order to study whether individual differences in the inten- sity in which they are experienced mediate relationships between traits and ERN amplitude or RFA. It would also be better if additional mood scores could be obtained after prolonged task performance but before the reward manipulation. In the present study, we did not measure mood at that point, because interrupting performance and measuring mood state could alter subsequent task engagement by itself. A limitation of the present model of constraint, absorption, and drive for reward is that it failed to predict the increase in ERN amplitude after the reward manipulation. This increase has been predicted in previous studies by neuroticism scores (Pailing \& Segalowitz, 2004; Tops et al., 2006).

To summarize, we showed that most of the traits that have been related to ERN amplitude in previous research have in common a relationship with the motivational trait of persistence. In addition, we showed that the traits interact with context to predict the ERN and RFA, such that trait-context combinations that are likely to be associated with increased engagement predict larger ERN amplitudes and RFA. Together, this supports the hypothesis that engagement may be a common underlying factor that predicts the amplitude of the ERN, which may also be reflected in RFA during performance of the flanker task. Our findings suggest that ERN and RFA may provide an invaluable tool for researchers who want to covertly monitor and study engagement during task performance.

\section{AUTHOR NOTE}

This research was supported by a Veni grant from the Netherlands Organization for Scientific Research (NWO) (451-07-013). Correspondence concerning this article should be addressed to M. Tops, Centre for Child and Family Studies, University of Leiden, P.O. Box 9555, 2300 RB Leiden, The Netherlands (e-mail: m.tops@rug.nl).

\section{REFERENCES}

Amodio, D. M., Master, S. L., Yee, C. M., \& Taylor, S. E. (2008). Neurocognitive components of the behavioral inhibition and activation systems: Implications for theories of self-regulation. Psychophysiology, 45, 11-19.

Ando, J., Suzuki, A., Yamagata, S., Kijima, N., Maekawa, H., ONO, Y., \& JANG, K. L. (2004). Genetic and environmental structure of Cloninger's temperament and character dimensions. Journal of Personality Disorders, 18, 379-393.

BALCONI, M., \& MAZZA, G. (2010). Lateralisation effect in comprehension of emotional facial expression: A comparison between EEG alpha band power and behavioural inhibition (BIS) and activation (BAS) systems. Laterality, 15, 361-384. doi:10.1080/13576500902886056

Berkman, E. T., \& Lieberman, M. D. (2010). Approaching the bad and avoiding the good: Lateral prefrontal cortical asymmetry distinguishes between action and valence. Journal of Cognitive Neuroscience, 22, 1970-1979. doi:10.1162/jocn.2009.21317

Boksem, M. A. [S.], Meijman, T. F., \& Lorist, M. M. (2006). Mental fatigue, motivation and action monitoring. Biological Psychology, 72, 123-132.

Boksem, M. A. S., \& Tops, M. (2008). Mental fatigue: Costs and benefits. Brain Research Reviews, 59, 125-139.

Boksem, M. A. S., Tops, M., Kostermans, E., \& De Cremer, D. (2008). Sensitivity to punishment and reward omission: Evidence from errorrelated ERP components. Biological Psychology, 79, 185-192.

Boksem, M. A. S., Tops, M., Wester, A. E., Meijman, T. F., \& Lorist, M. M. (2006). Error related ERP components and individual differences in punishment and reward sensitivity. Brain Research, 1101, 92-101. 
Burton, L., Pfaff, D., Bolt, N., Hadjikyriacou, D., Silton, N., KilGALLEN, C., ET AL. (2009). Effects of gender and personality on the Conners Continuous Performance Test. Journal of Clinical Experimental Neuropsychology, 30, 1-6.

Carleton, R. N., Abrams, M. P., \& Asmundson, G. J. (2010). The Attentional Resource Allocation Scale (ARAS): Psychometric properties of a composite measure for dissociation and absorption. Depression \& Anxiety, 27, 775-786. doi:10.1002/da.20656

Carlson, C. L., Booth, J. E., Shin, M., \& Canu, W. H. (2002). Parent-, teacher-, and self-rated motivational styles in ADHD subtypes. Journal of Learning Disabilities, 35, 104-113.

CARver, C. S., \& Connor-Smith, J. (2010). Personality and coping. Annual Review of Psychology, 61, 679-704.

Carver, C. S., \& White, T. L. (1994). Behavioural inhibition, behavioural activation, and affective responses to impending reward and punishment: The BIS/BAS scales. Journal of Personality \& Social Psychology, 67, 319-333.

Cavanagh, J. F., \& Allen, J. J. (2008). Multiple aspects of the stress response under social evaluative threat: An electrophysiological investigation. Psychoneuroendocrinology, 33, 41-53.

Cloninger, C. R., Pryzbeck, T. R., Svrakic, D. M., \& Wetzel, R. D. (1994). The Temperament and Character Inventory (TCI): A guide to its development and use. St. Louis: Center for Psychobiology of Personality.

Coan, J. A., \& Allen, J. J. (2003). Frontal EEG asymmetry and the behavioral activation and inhibition systems. Psychophysiology, $\mathbf{4 0}$, 106-114.

Corbetta, M., \& Shulman, G. L. (2002). Control of goal-directed and stimulus-driven attention in the brain. Nature Reviews Neuroscience, 3, 201-215.

Craig, A. D. (2009). How do you feel-now? The anterior insula and human awareness. Nature Reviews Neuroscience, 10, 59-70.

Cukrowicz, K. C., Taylor, J., Schatschneider, C., \& Iacono, W. G. (2006). Personality differences in children and adolescents with attention-deficit/hyperactivity disorder, conduct disorder, and controls. Journal of Child Psychology \& Psychiatry, 47, 151-159.

CulP, N. A. (2006). The relations of two facets of boredom proneness with the major dimensions of personality. Personality \& Individual Differences, 41, 999-1007.

DAVIDSON, R. J. (1992). Anterior cerebral asymmetry and the nature of emotion. Brain \& Cognition, 20, 125-151.

De Fruyt, F., McCrae, R. R., Szirmák, Z., \& Nagy, J. (2004). The Five-Factor Personality Inventory as a measure of the five-factor model: Belgian, American, and Hungarian comparisons with the NEO-PI-R. Assessment, 11, 207-215.

De la Rie, S. M., Duijsens, I. J., \& Cloninger, C. R. (1998). Temperament, character, and personality disorders. Journal of Personality Disorders, 12, 362-372.

De Pascalis, V., Varriale, V., \& D'Antuono, L. (2010). Event-related components of the punishment and reward sensitivity. Clinical Neurophysiology, 121, 60-76.

Dikman, Z. V., \& Allen, J. J. B. (2000). Error monitoring during reward and avoidance learning in high- and low-socialized individuals. Psychophysiology, 37, 43-54.

Dywan, J., Mathewson, K. J., Choma, B. L., Rosenfeld, B., \& SegalowITZ, S. J. (2008). Autonomic and electrophysiological correlates of emotional intensity in older and younger adults. Psychophysiology, 45, 389-397.

Elovainio, M., Kivimäki, M., Puttonen, S., Heponiemi, T., Pulkki, L., \& Keltikangas-Järvinen, L. (2004). Temperament and depressive symptoms: A population-based longitudinal study on Cloninger's psychobiological temperament model. Journal of Affective Disorders, 83 , 227-232.

Engels, A. S., Heller, W., Mohanty, A., Herrington, J. D., BanICH, M. T., WebB, A. G., \& Miller, G. A. (2007). Specificity of regional brain activity in anxiety types during emotion processing. Psychophysiology, 44, 352-363.

ERIKSEN, B. A., \& ERIKSEN, C. W. (1974). Effects of noise letters upon the identification of a target letter in a nonsense search. Perception \& Psychophysics, 16, 143-149.

Falkenstein, M., Hohnsbein, J., Hoormann, J., \& Blanke, L. (1990). Effects of errors in choice reaction tasks on the ERP under focused and divided attention. In C. H. M. Brunia \& A. W. K. Gaillard (Eds.),
Psychophysiological brain research (pp. 192-195). Tilburg: Tilburg University Press.

Ferreira, C., Deslandes, A., Moraes, H., Cagy, M., Basile, L. F., Piedade, R., \& Ribeiro, P. (2006). The relation between EEG prefrontal asymmetry and subjective feelings of mood following 24 hours of sleep deprivation. Arquivos de Neuro-psiquiatria, 64, 382-387.

Franken, I. H. A., Muris, P., \& Rassin, E. (2005). Psychometric properties of the Dutch BIS/BAS scales. Journal of Psychopathological Behavioral Assessment, 27, 25-30.

Fusar-Poli, P., Placentino, A., Carletti, F., Allen, P., Landi, P., AbBamonte, M., ET AL. (2009). Laterality effect on emotional faces processing: ALE meta-analysis of evidence. Neuroscience Letters, 452, 262-267.

Gehring, W. J., Coles, M. G. H., Meyer, D. E., \& Donchin, E. (1990). The error-related negativity: An event-related brain potential accompanying errors. Psychophysiology, 27, S34.

Gratton, G., Coles, M. G., \& Donchin, E. (1983). A new method for off-line removal of ocular artifact. Electroencephalography \& Clinical Neurophysiology, 55, 468-484

Gusnard, D. A., Ollinger, J. M., Shulman, G. L., Cloninger, C. R., Price, J. L., Van Essen, D. C., \& Raichle, M. E. (2003). Persistence and brain circuitry. Proceedings of the National Academy of Sciences, 100, 3479-3484

HajCaK, G., McDonald, N., \& Simons, R. F. (2004). Error-related psychophysiology and negative affect. Brain \& Cognition, 56, 189-197.

HajcaK, G., Moser, J. S., Yeung, N., \& Simons, R. F. (2005). On the ERN and the significance of errors. Psychophysiology, 42, 151-160.

Halvorsen, M., Wang, C. E., Richter, J., Myrland, I., Pedersen, S. K., EisemanN, M., \& Waterloo, K. (2009). Early maladaptive schemas, temperament and character traits in clinically depressed and previously depressed subjects. Clinical Psychology \& Psychotherapy, 16, 394-407.

Harmon-Jones, E., \& Allen, J. J. (1997). Behavioral activation sensitivity and resting frontal EEG asymmetry: Covariation of putative indicators related to risk for mood disorders. Journal of Abnormal Psychology, 106, 159-163.

Harmon-Jones, E., Gable, P. A., \& Peterson, C. K. (2010). The role of asymmetric frontal cortical activity in emotion-related phenomena: A review and update. Biological Psychology, 84, 451-462. doi:10.1016/j.biopsycho.2009.08.010

Hendriks, A. A. J., Hofstee, W. K. B., \& De RaAd, B. (1999). Handleiding bij de five-factor personality inventory (FFPI) [Manual to the five-factor personality inventory (FFPI)]. Lisse: Swets Test Publishers

KnyaZev, G. G., \& Slobodskoj-Plisnin, J. Y. (2007). Behavioural approach system as a moderator of emotional arousal elicited by reward and punishment cues. Personality \& Individual Differences, 42, 49-59.

KopP, B., Rist, F., \& Mattler, U. (1996). N200 in the flanker task as a neurobehavioral tool for investigating executive control. Psychophysiology, 33, 282-294.

Larson, M. J., Fair, J. E., Good, D. A., \& Baldwin, S. A. (2010). Empathy and error processing. Psychophysiology, 47, 415-424.

Laufs, H., Kleinschmidt, A., Beyerle, A., Eger, E., SaleKHaddadi, A., Preibisch, C., \& Krakow, K. (2003). EEG-correlated fMRI of human alpha activity. NeuroImage, 19, 1463-1476.

LuU, P., Collins, P., \& Tucker, D. M. (2000). Mood, personality, and self-monitoring: Negative affect and emotionality in relation to frontal lobe mechanisms of error monitoring. Journal of Experimental Psychology: General, 129, 43-60.

MacDonald, K. B. (2008). Effortful control, explicit processing, and the regulation of human evolved predispositions. Psychological Review, 115, 1012-1031.

Marchesi, C., Ampollini, P., DePanfilis, C., \& Maggini, C. (2008). Temperament features in adolescents with ego-syntonic or egodystonic obsessive-compulsive symptoms. European Child \& Adolescent Psychiatry, 17, 392-396.

Mathersul, D., Williams, L. M., Hopkinson, P. J., \& Kemp, A. H (2008). Investigating models of affect: Relationships among EEG alpha asymmetry, depression, and anxiety. Emotion, 8, 560-572.

NetTle, D. (2007). Empathizing and systemizing: What are they, and what do they contribute to our understanding of psychological sex differences? British Journal of Psychology, 98, 237-255. 
Olvet, D. M., \& HAJCAK, G. (2008). The error-related negativity (ERN) and psychopathology: Toward an endophenotype. Clinical Psychology Reviews, 28, 1343-1354.

Pailing, P. E., \& Segalowitz, S. J. (2004). The error-related negativity as a state and trait measure: Motivation, personality, and ERPs in response to errors. Psychophysiology, 41, 84-95.

Pivik, R. T., Broughton, R. J., Coppola, R., Davidson, R. J., Fox, N., \& Nuwer, M. R. (1993). Guidelines for the recording and quantitative-analysis of electroencephalographic activity in research contexts. Psychophysiology, 30, 547-558.

Potts, G. F., George, M. R. M., Martin, L. E., \& Barratt, E. S. (2006). Reduced punishment sensitivity in neural systems of behavior monitoring in impulsive individuals. Neuroscience Letters, 397, 130-134.

RabBit, P. M. A. (1966). Errors and error correction in choice-response tasks. Journal of Experimental Psychology, 71, 264-272.

Rankin, K. P., Rosen, H. J., Kramer, J. H., Schauer, G. F., Weiner, M. W., Schuff, N., \& Miller, B. L. (2004). Right and left medial orbitofrontal volumes show an opposite relationship to agreeableness in FTD. Dementia \& Geriatric Cognitive Disorders, 17, 328-332.

Roberts, B. W., Jackson, J. J., Burger, J., \& Trautwein, U. (2009). Conscientiousness and externalizing psychopathology: Overlap, developmental patterns, and etiology of two related constructs. Developmental Psychopathology, 21, 871-888.

Samuel, D. B., \& Widiger, T. A. (2010). A comparison of obsessivecompulsive personality disorder scales. Journal of Personality Assessment, 92, 232-240.

Santesso, D. L., \& Segalowitz, S. J. (2009). The error-related negativity is related to risk taking and empathy in young men. Psychophysiology, 46, 143-152.

Santesso, D. L., Segalowitz, S. J., \& Schmidt, L. A. (2005). Diminished error-related negativity in 10 -year-old children with poor social behavior. Biological Psychology, 70, 79-87.

Segerstrom, S. C. (2005). Optimism and immunity: Do positive thoughts always lead to positive effects? Brain, Behavior, \& Immunity, 19, 195-200.

Shackman, A. J., McMenamin, B. W., Maxwell, J. S., Greischar, L. L., \& Davidson, R. J. (2009). Right dorsolateral prefrontal cortical activity and behavioral inhibition. Psychological Science, 20, 1500-1506.

Sollberger, M., Stanley, C. M., Wilson, S. M., Gyurak, A., BeckMAN, V., Growdon, M., ET AL. (2009). Neural basis of interpersonal traits in neurodegenerative diseases. Neuropsychologia, 47, 28122827.

Stahl, J., \& GibBons, H. (2007). Dynamics of response-conflict monitoring and individual differences in response control and behavioral control: An electrophysiological investigation using a stop-signal task. Clinical Neurophysiology, 118, 581-596.

Stewart, J. L., Levin-Silton, R., Sass, S. M., Heller, W., \& Miller, G. A. (2008). Anger style, psychopathology, and regional brain activity. Emotion, 8, 701-713.

Tellegen, A. (1985). Structure of mood and personality and their relevance to assessing anxiety, with an emphasis on self-report. In A. H. Tuma \& J. D. Maser (Eds.), Anxiety and the anxiety disorders (pp. 681-706). Hillsdale, NJ: Erlbaum.

Tomarken, A. J., Davidson, R. J., Wheeler, R. E., \& Doss, R. C. (1992). Individual differences in anterior brain asymmetry and fundamental dimensions of emotion. Journal of Personality \& Social Psychology, 62, 676-687.
Tops, M., \& BoKsEM, M. A. S. (in press). Cortisol involvement in mechanisms of behavioral inhibition. Psychophysiology. doi:10.1111/j.1469 $-8986.2010 .01131 . x$

Tops, M., Boksem, M. A. S., Luu, P., \& Tucker, D. M. (2010). Brain substrates of behavioral programs associated with selfregulation. Frontiers in Psychology, 1(Art. 152), 1-14. doi:10.3389/ fpsyg.2010.0152.

Tops, M., BoKsem, M. A. S., Wester, A. E., Lorist, M. M., \& MeiJMAN, T. F. (2006). Task engagement and the relationships between the error-related negativity, agreeableness, behavioral shame proneness and cortisol. Psychoneuroendocrinology, 31, 847-858.

Tucker, D. M., Luu, P., Frishroff, G., Quiring, J., \& Poulsen, C. (2003). Frontolimbic response to negative feedback in clinical depression. Journal of Abnormal Psychology, 112, 667-678.

Tucker, D. M., LuU, P., \& Pribram, K. H. (1995). Social and emotional self-regulation. In J. Grafman, K. J. Holyoak, \& F. Bollar (Eds.), Structure and functions of the human prefrontal cortex (Annals of the New York Academy of Sciences, Vol. 769, pp. 213-239). New York: New York Academy of Sciences.

Wager, T. D., Sylvester, C. Y., Lacey, S. C., Nee, D. E., FrankLIN, M., \& JONIDES, J. (2005). Common and unique components of response inhibition revealed by fMRI. NeuroImage, 27, 323-340.

Wald, F. D. M., \& MellenberG, G. J. (1990). De verkorte versie van de Nederlandse vertaling van de Profile of Mood States (POMS) [Short version of the Dutch translation of the Profile of Mood States]. Nederlands Tijdschrift voor de Psychologie, 45, 86-99.

West, R., \& Travers, S. (2008). Tracking the temporal dynamics of updating cognitive control: An examination of error processing. $\mathrm{Ce}$ rebral Cortex, 18, 1112-1124.

Whittle, S., Allen, N. B., Lubman, D. I., \& Yücel, M. (2006). The neurobiological basis of temperament: Towards a better understanding of psychopathology. Neuroscience \& Biobehavioral Review, 30, 511-525.

WickRAMASEKERA, I. E., 2ND (2007). Empathic features of absorption and incongruence. American Journal of Clinical Hypnosis, 50, 59-69.

Wittfoth, M., Küstermann, E., Fahle, M., \& Herrmann, M. (2008). The influence of response conflict on error processing: Evidence from event-related fMRI. Brain Research, 1194, 118-129.

Woo, M., Kim, S., Kim, J., Petruzzello, S. J., \& Hatfield, B. D. (2009). Examining the exercise-affect dose-response relationship: Does duration influence frontal EEG asymmetry? International Journal of Psychophysiology, 72, 166-172.

Yeung, N., Holroyd, C. B., \& Cohen, J. D. (2005). ERP correlates of feedback and reward processing in the presence and absence of response choice. Cerebral Cortex, 15, 535-544.

\section{NOTE}

1. The measure of empathetic concern that predicted larger ERN amplitudes in the studies by Santesso and Segalowitz (2009) and Larson, Fair, Good, and Baldwin (2010) is highly related to the measure of agreeableness that predicted larger ERN amplitudes in the study by Tops et al. (2006). In fact, it has been found that this empathy measure "appears essentially equivalent to agreeableness in the five-factor model of personality" (Nettle, 2007).

(Manuscript received January 11, 2010; revision accepted for publication July 1, 2010.) 